\title{
Genetic diversity in chrysophytes: Comparison of different gene markers
}

\author{
Christina Bock ${ }^{1}$, Antonis Chatzinotas ${ }^{2,3}$ \& Jens BoenigK ${ }^{1,4}$
}

\author{
${ }^{1}$ Department of Biodiversity, University Duisburg-Essen, Universitaetsstrasse 5, D-45117 Essen, Germany \\ ${ }^{2}$ Department of Environmental Microbiology, Helmholtz Centre for Environmental Research - UFZ, Permos- \\ erstrasse 15, D-04318 Leipzig, Germany \\ ${ }^{3}$ German Centre for Integrative Biodiversity Research (iDiv) Halle-Jena-Leipzig, Deutscher Platz 5e, 04103 \\ Leipzig, Germany \\ ${ }^{4}$ Centre for Water and Environmental Research (ZWU), University of Duisburg-Essen, Universitaetsstr. 2, \\ 45117 Essen, Germany
}

\begin{abstract}
Chrysophytes are a diverse group of protists belonging to the Stramenopiles. They encompass a broad range of nutrition strategies (phototrophy, mixotrophy and heterotrophy) and morphological forms (unicellular, colonial, branched, non-scaled to silica-scaled). However, taxonomy, identification and delineation of genera and species are hampered by the polyphyletic origin of several morphotypes and the low resolution of morphological features; moreover, description of these features requires in many cases special equipment like TEM or SEM. To test the congruent phylogeny, genetic resolution and to reveal the genetic diversity of chrysophytes, we evaluated in this study different gene markers, in particular SSU and LSU rRNA genes, ITS, and COI in terms of phylogenetic clustering, separation of phylogenetic lineages and genetic distances within and between clades. Our results showed that the general topology of the SSU rRNA gene phylogeny is similar to that of the LSU rRNA gene phylogeny, with a higher genetic divergence for the latter. The topology of the COI phylogeny differed from the ribosomal data, and showed the highest genetic divergence within groups and between groups for all compared markers. The 5.8S rRNA gene offered only a limited phylogenetic resolution with low genetic divergence. ITS showed a high genetic divergence, but phylogenetic analyses were hampered by high variance in sequence lengths between clades.
\end{abstract}

Key words: Chrysophyceae, SSU, LSU, COI, ITS

\section{INTRODUCTION}

Chrysophyceae sensu lato (chrysophytes), the so called "golden algae", comprise the groups of Synurales, Ochromonadales, Chromulinales and others within the Stramenopiles (ANDERSEN et al. 1999; Kristiansen \& Preisig 2007; JoRdan \& IwATAKi 2012). They represent an abundant and in some environments even dominating group of planktonic protists (RоTт 1988; TоLOTTI et al. 2003, 2006; Kammerlander et al. 2015). They occur in a broad range of ecotypes and comprise heterokont biflagellate eukaryotes, which received their common name due to the golden-brown color of the accessory pigment fucoxanthin present in some of their members (Bellinger \& Sigee 2013). The morphology of chrysophytes ranges from unicellular (e.g. Ochromonas) to colonial (e.g. Synura) or branching forms (e.g. Hydrurus). Non-scaled as well as silicascaled taxa (belonging either to the Synurales [or Synurophyceae], Paraphysomonadida or Chrysosphaerella) belong to this diverse group of protists (ŠKALOUD et al. 2013; ŠKALOUdOVÁ \& ŠKaloud 2013). They encompass varying nutritional strategies, including phototrophy, mixotrophy and heterotrophy with both phagotrophy by ingesting bacteria (THINGSTAD et al.1996; KAMJUNKE et al. 2007; UnReIn et al. 2007) or osmotrophy (PRINGSHEIM 1952). Despite the broad range of morphological forms, identification and thus distinction of members belonging to the same genus or even to closely related genera is often problematic. Species delineations are usually based on small morphological differences. These features as for example the scale morphology in Synura or Paraphysomonas can often only be detected with special equipment like transmission electron microscopy (TEM) or scanning electron microscopy (SEM) (ŠKaloud et al. 2012; Scoble \& CavalierSмiтн 2014). The fact that morphology may change under different environmental conditions because of phenotypic plasticity adds to the difficulties of species delimitation (Luo et al. 2006).

With the advent of marker-based phylogenetic ap- 
proaches, new light was shed into the taxonomy and phylogenetic relationship of this group (ANDERSEN et al. 1999). Molecular analyses revealed that some morphotypes are in fact polyphyletic and form separate clusters within the chrysophytes, showing that classification solely based on morphology is sometimes misleading (Grossmann et al. 2016). One good example are colorless, nonscaled chrysophytes which are genetically far more diverse than morphology reflects (Boenigk et al. 2005; Pfandl et al. 2009; Findenig et al. 2010). Several new genera were recently erected mainly based on molecular identification, since light microscopy could not distinguish between isolates belonging to different phylogenetic lineages (GROSSMANN et al. 2016). Even TEM and SEM offer only a limited amount of information within this species complex (Findenig et al. 2010). A huge hidden diversity was also observed within species complexes of Paraphysomonas, which lead to the establishment of several new species; it is very likely, that even more species exist since environmental surveys have detected additional undescribed phylogenetic lineages within the Paraphysomonadidae (ScoBle \& CAVAlIER-SMith 2014).

In the past, biodiversity and monitoring questions in freshwater systems were mainly addressed based on morphological data (e.g. PADISÁK et al. 1998). With the new knowledge gained from molecular biological approaches, environmental surveys can overcome the risks associated with campaigns solely based on morphology of organisms, namely to miss cryptic species complexes and to lose information regarding their geographical and /or seasonal distribution.

Many studies base their results on SSU rRNA gene data. Even if the SSU rRNA gene offers a good backbone for the phylogeny within protist groups, it was shown in several studies that this genetic marker might be too conserved to reveal the occurring genetic diversity within related lineages (Bock et al. 2010; NASSONOVA et al. 2010; ŠKALOUd et al. 2012). Within the Synura petersenii complex, six genetic lineages were revealed by multiple genetic markers (internal transcribed spacer rDNA, psaA, rbcL and COI) which were further supported by morphological data based on TEM and SEM of silica scales (Š́KALOUD et al. 2010). This combination of morphological and molecular data allowed the authors an additional interpretation on the diversity and distribution patters. These results demonstrate the need of phylogenetic markers with high resolution and reliable stable topology to distinguish between closely related species and thus to obtain reliable information about phylogenetic relationships of chrysophytes and their distribution.

Here, we present comparative analyses of the SSU rRNA gene, the ITS1-5.8S-ITS2 sequence region, the D1-D2 region of the LSU rRNA gene and COI sequences from a huge range of different chrysophytes. We analyzed phylogeny, genetic distances within and between clades with respect to reliable and stable topology and phylogenetic lineage distinction. The main aim of this paper was to find a suitable marker region for a stable phylogeny, which further allows a good separation between closely related lineages.

\section{Material And Methods}

Isolates and culture conditions. Most strains were isolated during sampling campaigns in 2002 and 2006. Isolation and maintenance of strains were conducted as already described in BoEnIGK et al. (2005). For details on origin of the isolates see table S1. Isolates were discarded after the DNA-extraction.

DNA isolation, amplification and sequencing. For DNA isolation, cells were harvested by centrifugation at $14000 \times \mathrm{g}$ and the resulting pellet was used for DNA extraction. DNA was extracted using the DNeasy Tissue kit (Qiagen Gmbh Hilden, Germany) and amplified separately for the different gene regions (details on used primers see table S2).

Phylogenetic analyses. Four different alignments were constructed for the phylogenetic analyses with the newly obtained sequences and additional sequences obtained from NCBI (http://www.ncbi.nlm.nih.gov/). Reference sequences representing the different clades of the Chrysophyceae were selected on the basis of previous publications (e.g. MEDINGER et al. 2010; Silberfeld et al. 2010; Klaveness et al. 2011; Bock et al 2014). The sequences were initially aligned using ClustelW (Thompson et al. 1994) and adjusted by eye using the SequentiX Alignment Editor (Hepperle 2004). Only highly ambitious regions were excluded from the analyses. The phylogeny of the SSU rRNA gene (Fig1-2, FigS1) was inferred from an aligned dataset including 238 sequences based on 1206 characters. The sequences Synchroma grande DQ788730, Leukarachnion sp. FJ356265 were chosen as outgroup according to Bock et al. (2014). LSU rRNA gene phylogeny was inferred from 175 sequences with 615 characters (Fig 3, FigS2). COI phylogeny was interfered from 139 sequences with 421 characters (Fig 4, FigS4). ITS phylogeny was interfered from 17 sequences with 902 characters (Fig 5). The 5.8S rRNA gene phylogeny was interfered with 95 sequences and 132 characters (Fig S3). All phylogenetic trees (except for ITS) presented here were inferred by maximum likelihood settings with RAXML 8.2.9 (STAMATAKIS 2014)using the Cipres gateway (MiLler et al. 2010). Models for ITS were used as proposed by Treefinder under AICc criteria: partitioned dataset (ITS1: HKY[Optimum,Empiri cal]:G[Optimum]:5，5.8S: HKY[ $\{3,1,1,1,1,3\}$,Empirical], ITS2: TVM[Optimum,Empirical]:G[Optimum]:5 $\} ; \quad 5.8 \mathrm{~S}$ : $\operatorname{HKY}[\{3,1,1,1,1,3\}$,Empirical). To test the confidence of the tree topologies, bootstrap analyses were carried out for distance (neighbor-joining, NJ; 1000 pseudoreplicates) and maximum parsimony analyses (MP, 1000 pseudoreplicates; with heuristic search options based on random taxon addition, tree-bisection-reconnection (TBR) branch swapping algorithm and Multrees option enabled) using PAUP*, portable version 4.0b10 (SWOFFord 1993), and for maximum likelihood (ML, 1000 pseudoreplicates; settings as described above) respectively. Bayesian analyses were carried out using MrBayes 3.2.6 via the Cipres portal (MilLer et al. 2010). For each presented tree, two runs with four chains of Markov 
chain Monte Carlo (MCMC) iterations were performed with 10.000 .000 generations with tree sampling every 100 generations. The GTR $+\mathrm{G}$ model with gamma shape parameter was chosen for the datasets. Tracer V1.4 (RAmbaut \& DRummond 2007) was used to check the stationary phase and to identify an appropriate burn in value. The first $25 \%$ of the trees were discarded as burn-in and 50\% majority-rule consensus trees were calculated for posterior probabilities.

Average genetic distances in different clades. Av e r a g e mean distances based on the K2P option were calculated for different clades and sequences by using Mega 5.2.2. All ambiguous positions were removed for each sequence pair. The sequences were group based on their phylogenetic position within the SSU rRNA gene phylogeny: Ochromonadales (containing the genera Poteriospumella, Spumella, Pedospumella and Dinobryon); Synurales, Paraphysomondadia, Apoikiida, Chromulinales (details about assignment to groups see table S1). Average mean divergences within groups (Fig 6) and between groups (Fig 7) were compared for the gene regions: partial SSU rRNA gene (1165 characters), V4 region of the SSU rRNA gene (197 characters), 5.8S rRNA gene (132 characters), D1-D2 region of LSU rRNA gene (615 characters) and COI (420 characters). Amount of sequences compared are noted in Tables S3, S4 and correspond to the sequences within the phylogenies. The Ochromonadales were separated into the genera Poteriospumella, Pedospumella and Spumella for the ITS1 and ITS2 divergence since suitable alignment over the whole clade was not possible.

\section{Results}

In a first step, phylogenies were calculated to compare the cluster pattern of the isolates for the different gene
regions.Subsequently, average mean distances based on the K2P model within and between different clades were calculated for the different gene markers. All genetic regions, including variable parts, were included in the phylogenies to allow a detailed comparison between genetic distances and corresponding phylogeny. 360 new chrysophyte sequences including LSU rRNA gene (rRNA), SSU rRNA gene (rRNA), COI (including sequences with TGA codon) and ITS were obtained by PCR for the purpose of this study and have been made publicly available (details on accession numbers and analyzed strains see Table S1). Due to amplification problems, not all isolates could be sequenced for all mentioned marker regions. Selected sequences of the occurring clades available from GenBank were downloaded and used as references within the phylogenies (Figs1-5, S1-4).

\section{The general topology of SSU rRNA gene, LSU rRNA gene, COI}

The general topology of the SSU phylogeny is in congruence with previously published studies. Labeling of clades was done according to Pfande et al. (2009) and Grossmann et al. (2016). Clades including the Chromulinales, Paraphysomonadida, Hydrurales, Hibberdiales, Synurales and Ochromonadales were resolved in our study with various statistical supports (Figs 1-2, Fig S1). The unrooted LSU rRNA gene phylogeny (Fig 3, Fig S2) showed a similar topology compared to the SSU phylogeny. Several clades could only be represented with one sequence in the LSU rRNA gene phylogeny as for example Hydrurus and Segregatospumella. The order of the main groups (e.g. Apoikiida, Chromulinales, Synurales, Hydrurales, Ochromon-

Table 1. Estimates of average evolutionary divergence between sequences for the ITS1-5.8S-ITS2. All positions containing gaps and missing data were eliminated. Analyses were conducted using the Kimura 2-parameter model. Evolutionary analyses were conducted in MEGA5 (TAMURA et al. 2011). The number of base substitutions per site from averaging over all sequence pairs within each group are shown.

\begin{tabular}{|c|c|c|c|c|c|c|c|c|c|c|c|c|c|c|c|}
\hline & $194 \mathrm{f}$ & 1305 & 1058 & 1031 & $186 \mathrm{hm}$ & $199 \mathrm{hm}$ & $367 \mathrm{hm}$ & JBL14 & JBM09 & 391f & AR4A6 & JBNA45 & $9-10-\mathrm{C} 1$ & 1020 & 1026 \\
\hline $194 \mathrm{f}$ & & & & & & & & & & & & & & & \\
\hline 1305 & 0.1813 & & & & & & & & & & & & & & \\
\hline 1058 & 0.1928 & 0.0462 & & & & & & & & & & & & & \\
\hline 1031 & 0.1813 & 0.0000 & 0.0462 & & & & & & & & & & & & \\
\hline $186 \mathrm{hm}$ & 0.1928 & 0.0462 & 0.0000 & 0.0462 & & & & & & & & & & & \\
\hline $199 \mathrm{hm}$ & 0.1928 & 0.0462 & 0.0000 & 0.0462 & 0.0000 & & & & & & & & & & \\
\hline $367 \mathrm{hm}$ & 0.1905 & 0.0386 & 0.0126 & 0.0386 & 0.0126 & 0.0126 & & & & & & & & & \\
\hline JBL14 & 0.2258 & 0.1502 & 0.1349 & 0.1502 & 0.1349 & 0.1349 & 0.1370 & & & & & & & & \\
\hline JBM09 & 0.2235 & 0.1480 & 0.1327 & 0.1480 & 0.1327 & 0.1327 & 0.1349 & 0.0036 & & & & & & & \\
\hline $391 f$ & 0.2282 & 0.1413 & 0.1327 & 0.1413 & 0.1327 & 0.1327 & 0.1349 & 0.0274 & 0.0292 & & & & & & \\
\hline AR4A6 & 0.2969 & 0.2027 & 0.2051 & 0.2027 & 0.2051 & 0.2051 & 0.2125 & 0.2382 & 0.2382 & 0.2334 & & & & & \\
\hline JBNA45 & 0.3356 & 0.2693 & 0.2797 & 0.2693 & 0.2797 & 0.2797 & 0.2717 & 0.3124 & 0.3177 & 0.3145 & 0.2329 & & & & \\
\hline 9-10-C1 & 0.3377 & 0.2641 & 0.2665 & 0.2641 & 0.2665 & 0.2665 & 0.2718 & 0.3034 & 0.3087 & 0.3062 & 0.2086 & 0.0615 & & & \\
\hline 1020 & 0.2210 & 0.1767 & 0.1905 & 0.1767 & 0.1905 & 0.1905 & 0.1905 & 0.2432 & 0.2409 & 0.2381 & 0.2900 & 0.3415 & 0.3164 & & \\
\hline 1026 & 0.2579 & 0.2045 & 0.2069 & 0.2045 & 0.2069 & 0.2069 & 0.2116 & 0.2507 & 0.2482 & 0.2356 & 0.2866 & 0.3437 & 0.3382 & 0.0994 & \\
\hline JBNZ39 & 0.2836 & 0.2027 & 0.1909 & 0.2027 & 0.1909 & 0.1909 & 0.1981 & 0.2188 & 0.2188 & 0.2093 & 0.0330 & 0.2282 & 0.2135 & 0.2977 & 0.2814 \\
\hline
\end{tabular}




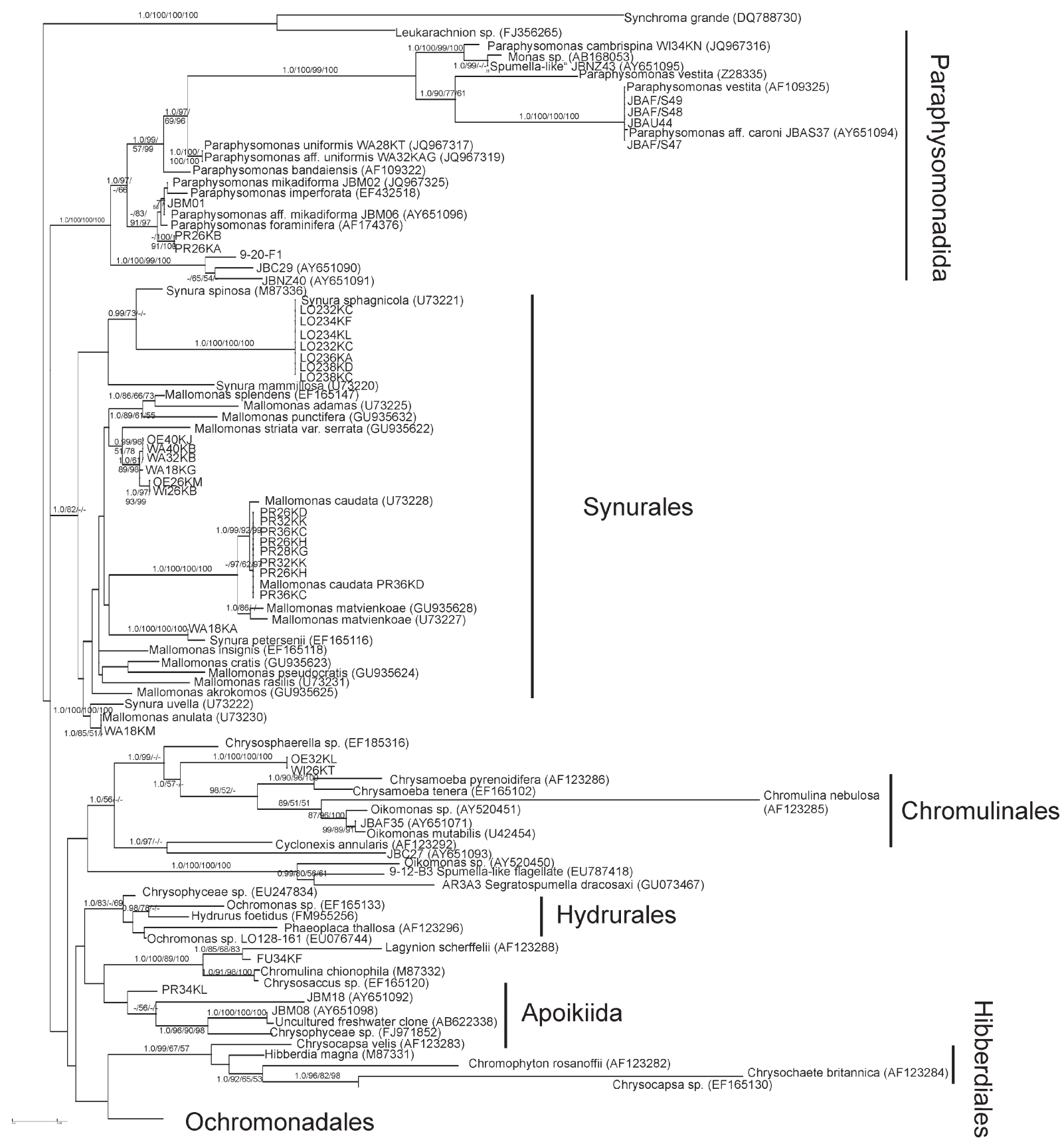

Fig 1. Phylogeny of the chrysophytes obtained by maximum likelihood inference of the SSU rDNA dataset. Values at the nodes indicate statistical support estimated by four methods—-Bayesian inference (MB), maximum likelihood (ML), maximum parsimony (MP), distance (neighbor joining; NJ). Hyphens indicate support below $50 \%$ for ML, MP, NJ and below 0.95 for MB. Scale bar represents the expected number of substitutions per site. Some phylogenetic lineages are collapsed and only the number of sequences within the lineage is shown. Ochromonadales are omitted and shown in Fig 2. The complete phylogeny including all used sequences is shown in Fig S1.

adales) were not statistically supported in either SSU or in LSU phylogeny. In the SSU phylogeny the clade containing Segregatospumella clusters outside the Ochromonadales forming an own clade (without statistical support for the actual placement) (Figs 1-2). Based on LSU rRNA gene data, Segregatospumella clusters with a long branch within the Ochromonadales without statistical support (Fig 3). The 5.8S rRNA gene phylogeny showed only a limited resolution for different phylogenetic lineages (Fig S3).

The COI phylogeny (Fig 4, Fig S4) shows a dif- ferent topology and clustering of the strains as compared to the ribosomal data. Support for main phylogenetic lineages and groups was not achieved. Even supported groups based on SSU have no support based on COI e.g. Synurales, Paraphysomonadia or Ochromonadales.

\section{Average genetic distances in different clades}

Average mean divergences within groups were compared for the gene regions: partial 18S rRNA gene, V4 region of the SSU rRNA gene, 5.8S rRNA gene, D1- 


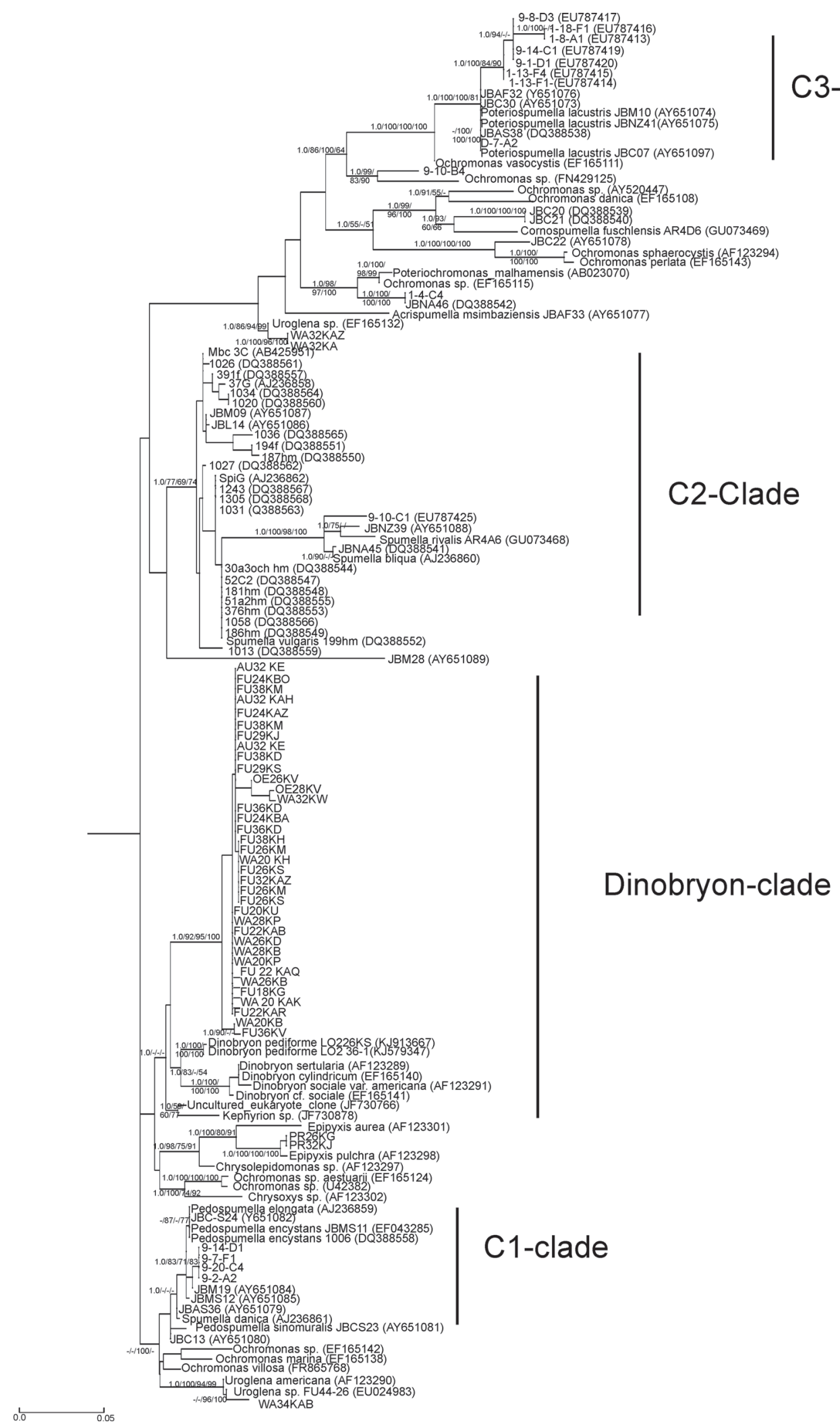

Fig 2. Phylogeny of the Ochromonadales obtained by maximum likelihood inference of the SSU rDNA dataset. Values at the nodes indicate statistical support estimated by four methods-Bayesian inference (MB), maximum likelihood (ML), maximum parsimony (MP), distance (neighbor joining; NJ). Hyphens indicate support below $50 \%$ for ML, MP, NJ and below 0.95 for MB. Scale bar represents the expected number of substitutions per site. Some phylogenetic lineages are collapsed and only number of sequences within the lineage is shown. 


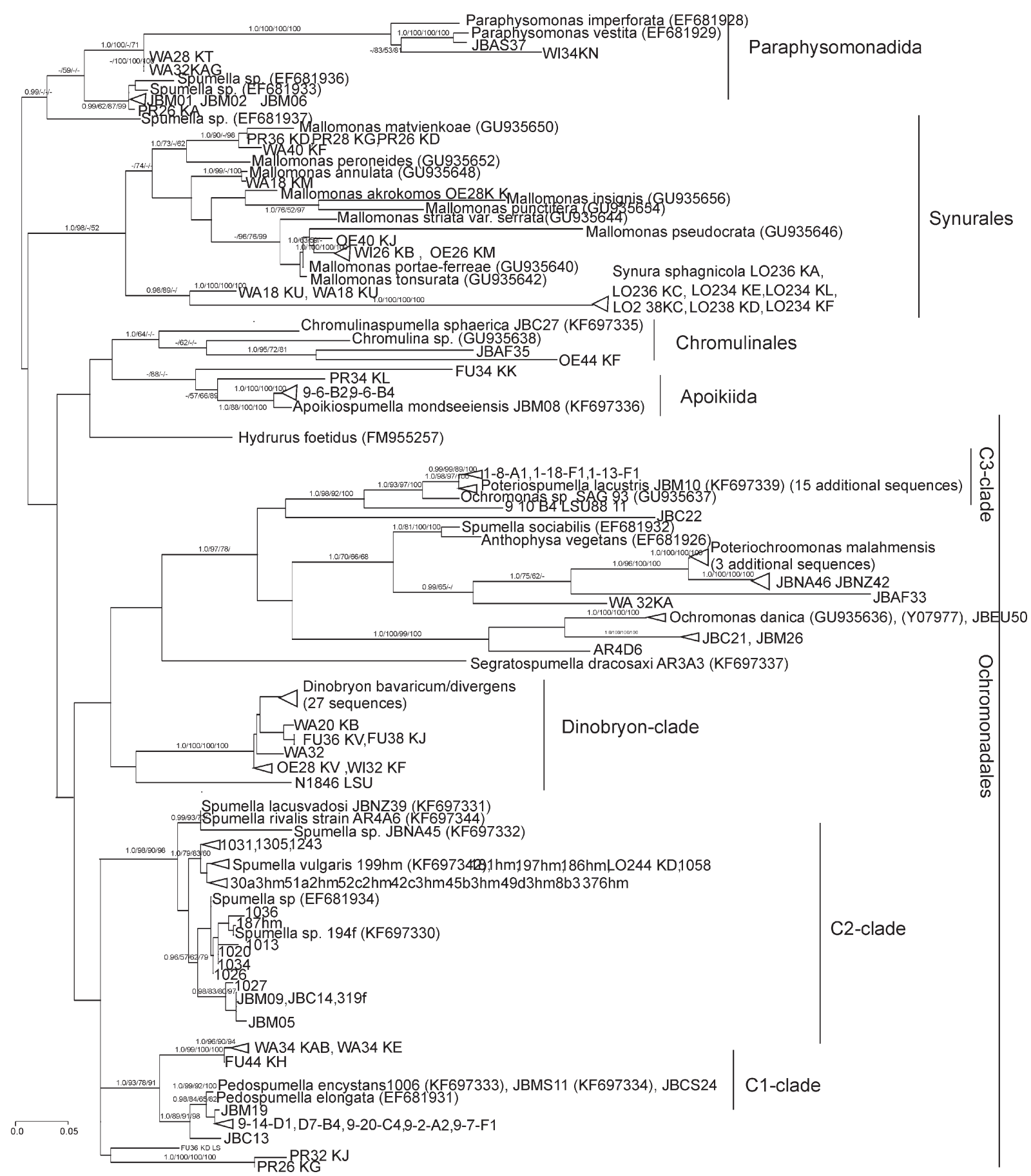

Fig 3. Phylogeny of the chrysophytes obtained by maximum likelihood inference of the LSU D1-D2 rDNA dataset. Values at the nodes indicate statistical support estimated by four methods-Bayesian inference (MB), maximum likelihood (ML), maximum parsimony (MP), distance (neighbor joining; NJ). Hyphens indicate support below 50\% for ML,MP, NJ and below 0.95 for MB. Scale bar represents the expected number of substitutions per site. Some phylogenetic lineages are collapsed and only number of sequences within the lineage is shown. Complete phylogeny including all sequences used is shown in Fig S2.

D2 region of LSU rRNA gene and COI (Fig 6). The highest divergence within groups was observed for the COI region (0.21-0.28), followed by LSU rRNA gene $(0.22-0.11)$ and the V4 rRNA gene region (0.04-0.11). $5.8 \mathrm{~S}$ rRNA gene and SSU show the smallest variation within groups $(0.01-0.06$ respectively $0.02-0.04)$ (details see table S3). The mean divergence between groups for the analyzed markers can be observed in
Fig 7 and table S4. Highest average divergences between groups were observed for the COI gene, LSU rRNA gene shows bit lower divergences. SSU divergences ranges between $0.05-0.06$; $\mathrm{V} 4$ varies between $0.11-0.17$; 5.8S rRNA gene between $0.07-0.11$. The ITS was exemplarily analyzed for divergences within groups of the $\mathrm{C} 2$-clade of the Ochromonadales (see table 1, Fig 5). The distances vary between $0.0-0.34$. 


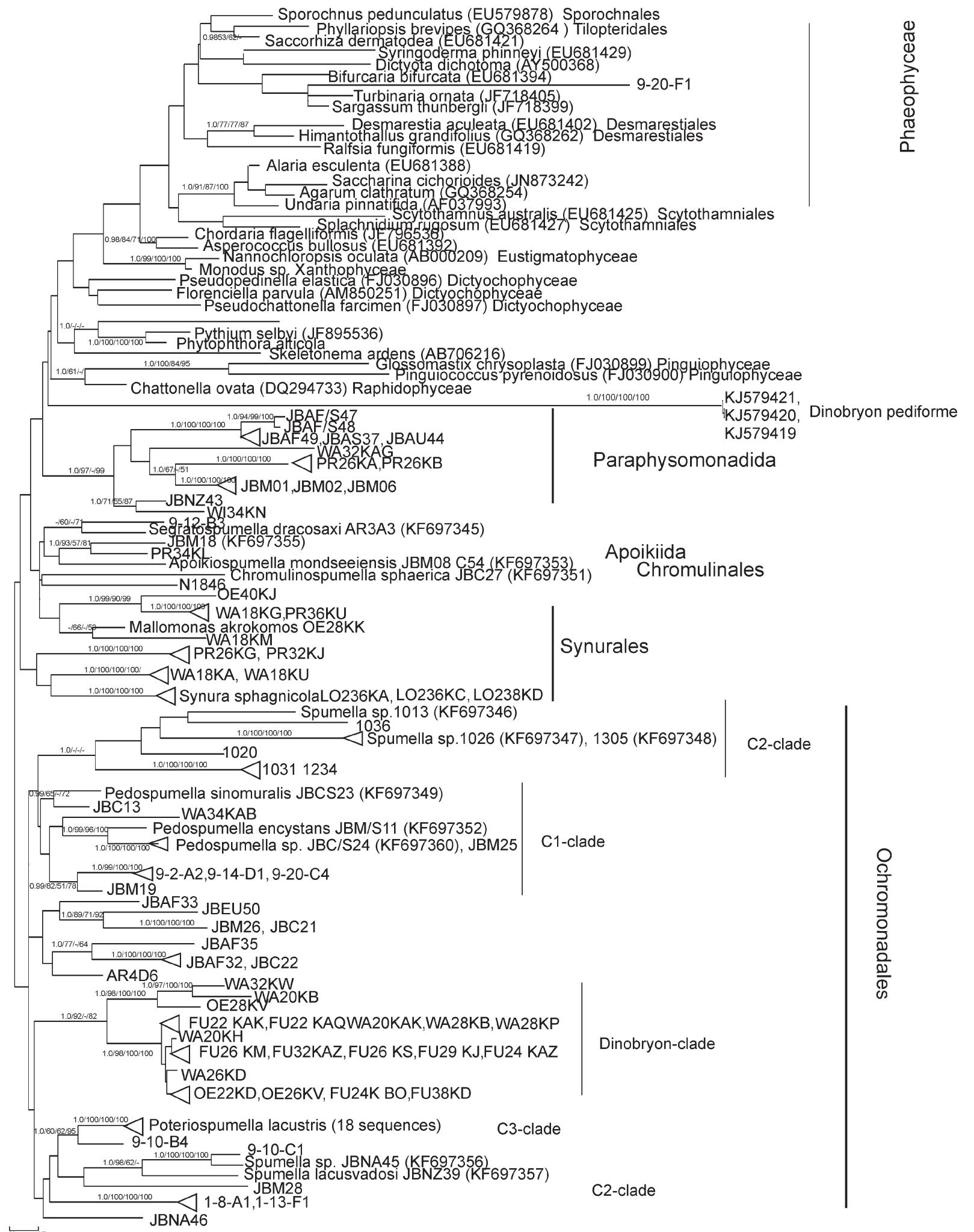

Fig 4. Phylogeny of the chrysophytes obtained by maximum likelihood inference of the COI dataset. Values at the nodes indicate statistical support estimated by four methods-Bayesian inference (MB), maximum likelihood (ML), maximum parsimony (MP), distance (neighbor joining; NJ). Hyphens indicate support below 50\% for ML,MP, NJ and below 0.95 for MB. Scale bar represents the expected number of substitutions per site. Some phylogenetic lineages are collapsed and only number of sequences within the lineage is shown. Complete phylogeny including all sequences used is shown in figure S4. 


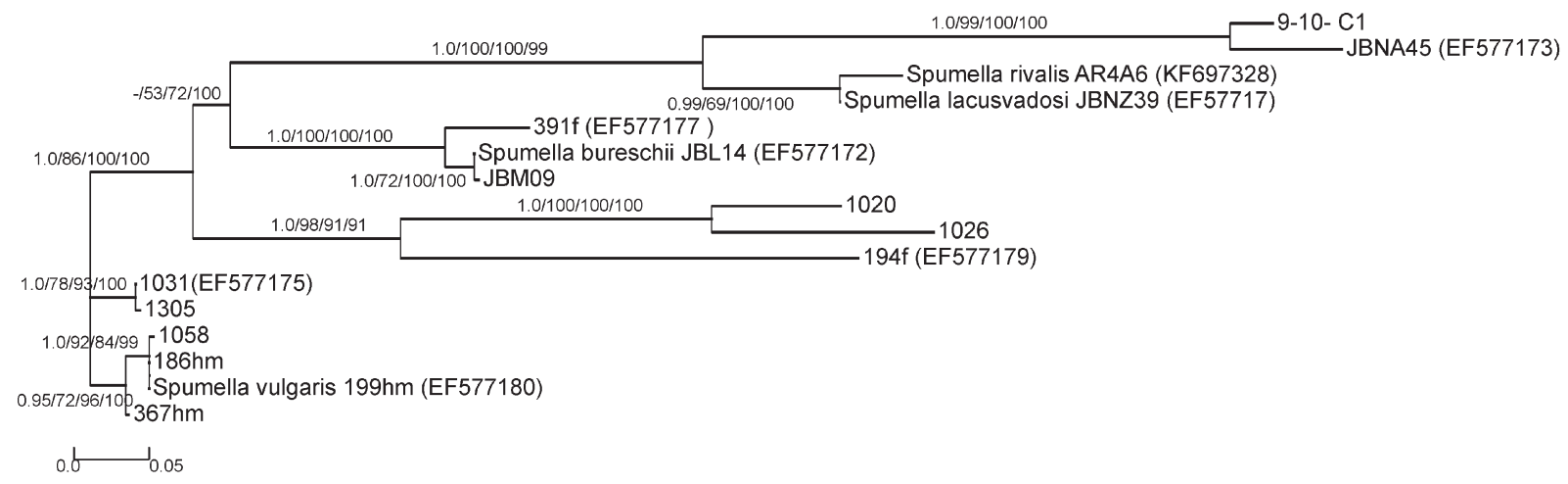

Figure 5. Phylogeny of the C2-clade obtained by maximum likelihood inference of the ITS rDNA dataset. Values at the nodes indicate statistical support estimated by four methods - Bayesian inference (MB), maximum likelihood (ML), maximum parsimony (MP), distance (neighbor joining; NJ). Hyphens indicate support below $50 \%$ for ML,MP, NJ and below 0.95 for MB. Scale bar represents the expected number of substitutions per site.

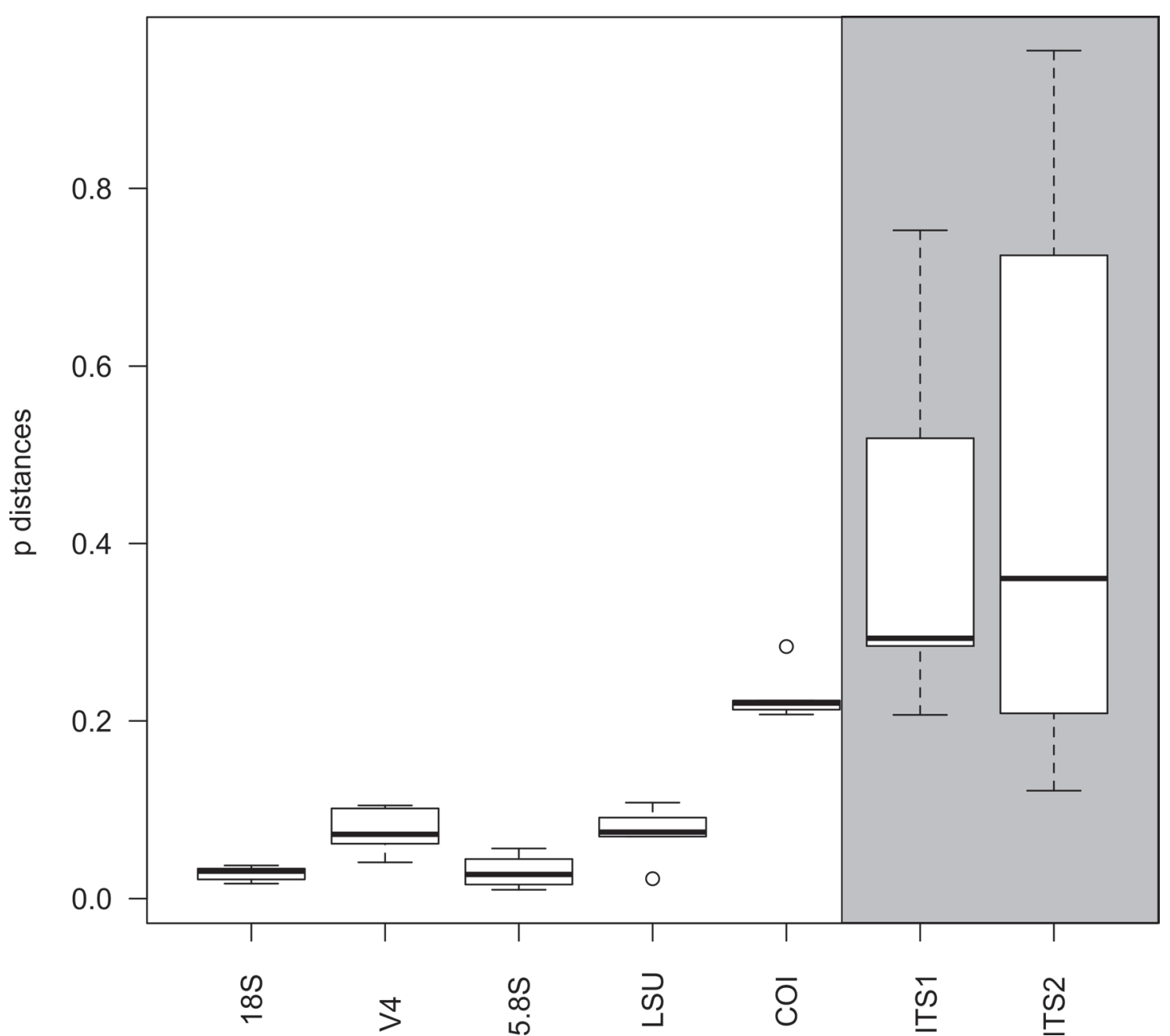

Figure 6. Average mean divergences within groups of chrysophytes. Estimates were conducted using the Kimura 2-parameter model using MEGA5 (TAMAMURA et al. 2011). All ambiguous positions were removed for each sequence pair. Amount of compared sequences (n) varied between genes and groups: Ochromonadales (Poteriospumella (18S n=14, V4 $\mathrm{n}=15,5.8 \mathrm{~S} \mathrm{n}=15$, LSU $\mathrm{n}=16$, COI $\mathrm{n}=24$ ), Spumella (18S $\mathrm{n}=24$, V4 n=25, 5.8S n= 22, LSU n=33, COI n=11, ITS1 n=17, ITS2 n=17), Pedospumella (18S n=13, V4 n=13, 5.8S n=8, LSU n=11, COI n=10, ITS1 n=9, ITS2 n=9), Dinobryon ( $18 \mathrm{~S}$ n=38, V4 n=38, 5.8S n= 7, LSU n=35, COI $n=20$, ITS1 n=7, ITS2 n=7)), Synurales $(18 S \mathrm{n}=24$, V4 $\mathrm{n}=24,5.8 \mathrm{~S} n=13$, LSU n=27, COI n=10, ITS1 $\mathrm{n}=11$, ITS $2 \mathrm{n}=11$, , Paraphysomonas $(18 \mathrm{~S} \mathrm{n}=15, \mathrm{~V} 4 \mathrm{n}=16,5.8 \mathrm{~S} \mathrm{n}=7, \mathrm{LSU} \mathrm{n}=12$, COI $\mathrm{n}=14$, ITS1 $\mathrm{n}=0$, ITS2 $\mathrm{n}=9$ ), Apoikiida (18S n=3, V4 n=3, 5.8S n= 2, LSU $n=4$, COI $n=3$, ITS1 $n=2$, ITS2 $n=2$ ), Chromulinales $(18 S \mathrm{n}=3$, V4 $n=4$, $5.8 \mathrm{~S} n=1, \mathrm{LSU} \mathrm{n}=4$, COI n $=2$, ITS1 n $=0$, ITS $2 \mathrm{n}=0$ ). The Ochromonadales were separated into the genera Poteriospumella, Pedospumella and Spumella for the ITS1 and ITS2 divergence since suitable alignment over the whole clade was not possible Details shown in table S3. 


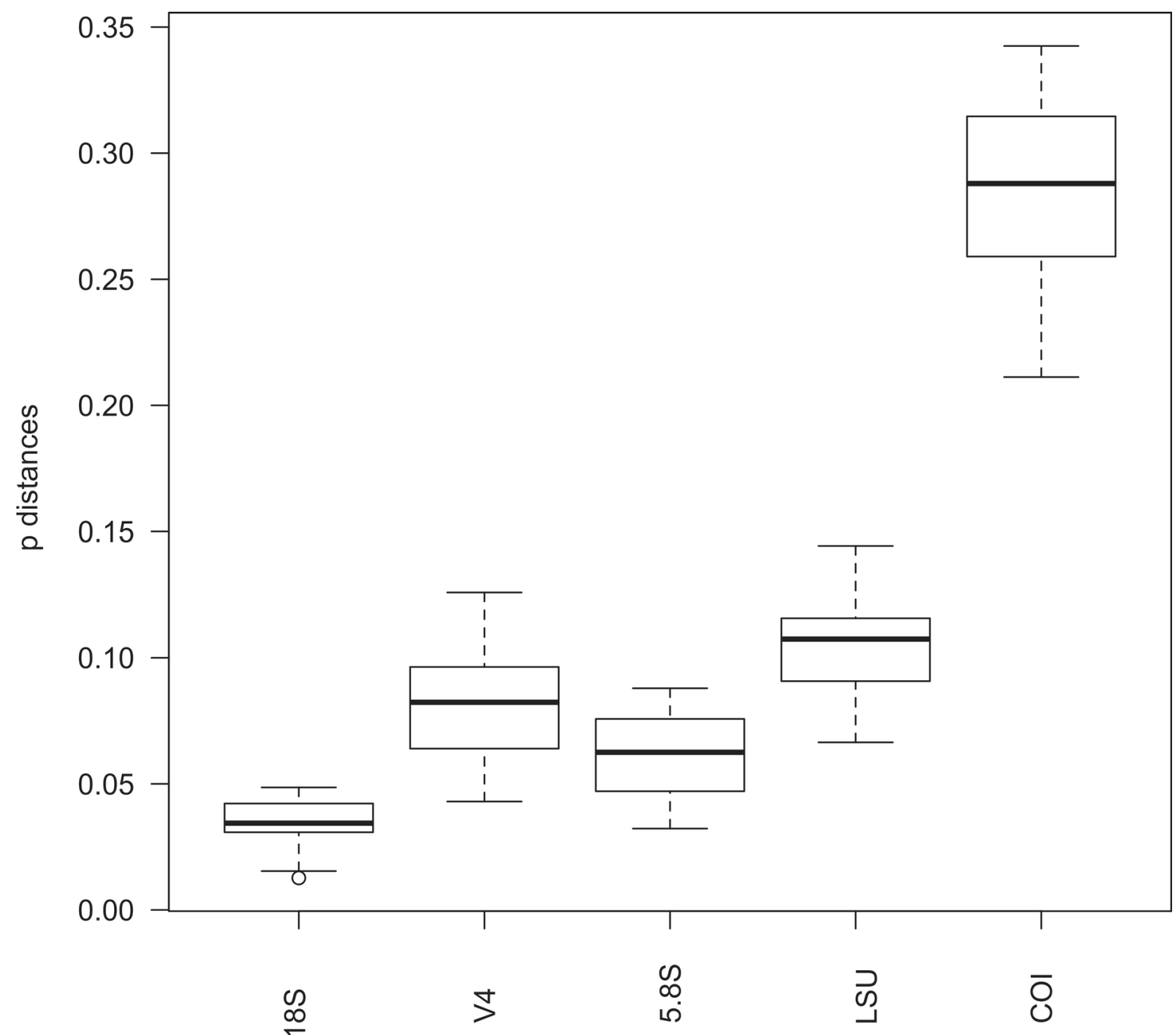

Figure 7. Estimates of average evolutionary divergence between groups for selected gene markers. All positions containing gaps and missing data were eliminated. Analyses were conducted using the Kimura 2-parameter model using MEGA5 (TAMURA et al. 2011). Details about number of base substitutions are shown in table S4. Ochromonadales ( $18 \mathrm{~S} n=80, \mathrm{~V} 4 \mathrm{n}=80,5.8 \mathrm{~S} n=42, \mathrm{LSU} \mathrm{n}=95$, COI $\mathrm{n}=66$ ), Synurales (18S $\mathrm{n}=24, \mathrm{~V} 4 \mathrm{n}=24,5.8 \mathrm{~S} n=13$, LSU n=27, COI n=10), Paraphysomonas $(18 \mathrm{~S} \mathrm{n}=15, \mathrm{~V} 4 \mathrm{n}=16,5.8 \mathrm{~S} \mathrm{n}=7$, LSU n=12, COI n=14), Apoikiida (18S $\mathrm{n}=3$, V4 $\mathrm{n}=3,5.8 \mathrm{~S} \mathrm{n}=2$, LSU $\mathrm{n}=4$, COI $\mathrm{n}=3$ ), Chromulinales $(18 \mathrm{~S} \mathrm{n}=3, \mathrm{~V} 4 \mathrm{n}=4,5.8 \mathrm{~S} \mathrm{n}=1$, LSU $\mathrm{n}=4$, COI $\mathrm{n}=2)$.

Analyses between clades for the ITS region were not possible due to the high variance in lengths.

\section{Discussion}

The application of molecular markers for distinguishing protist species and/or assessing diversity patterns in different environments is nowadays an established method (KRIENITZ \& BocK 2012; LeLIAERT et al. 2014). In phylogenetic studies, gene markers like the SSU rRNA gene, sometimes in combination with other markers, are regularly used to reveal phylogenetic relationships (Jo et al. 2013; ŠKALOUD et al. 2014). Our results confirm previous results that the SSU offers good phylogenetic resolution on genus level, but is in part too conserved to differentiate between closely related lineages as already reported from different other organisms (Piganeau et al. 2011; Leliaert et al. 2014;
AnNenkova et al. 2015). More rarely is the LSU used to show phylogenetic relationships. In our study the D1-D2 region showed high potential as a phylogenetic marker. The phylogeny is in general congruent with phylogenies obtained from SSU data (see Fig 1, Fig 3; Grossmann et al. 2016) even if statistical support for main groups is not as high. The LSU shows high genetic variance within clades and between clades. Similar good results were already obtained from studies on cercozoa (Wylezich et al. 2010) and ciliates (STOECK et al. 2014). In addition, the analyzed D1-D2 is a relative short region which makes it suitable for NGS sequencing techniques. In how far the primers might be suitable for universal amplification of protists needs still to be addressed.

Several studies on chrysophytes have evaluated the $\mathrm{COI}$ as a marker region for phylogenetic analyses. It was shown, for instance, that it is indeed a highly variable region, suitable for distinguishing closely related lineages (Jost et al. 2010; Bock et al. 2014). Jost 
et al. (2010) showed that the COI region is suitable to distinguish Dinobryon divergens from D. bavaricum strains, which is nearly impossible based on SSU rRNA gene analyses. Our analyses confirmed the high degree of variation for chrysophytes. Nevertheless, we came across several problems. Even if the average divergence between groups is high, the evolutionary divergence within groups is nearly as high (Figs 6,7). The appearance of TGA codons in the C1-C2 kinship is also striking. The extent to which TGA serves as a stop codon is controversially discussed. Studies on closely related groups suggest that the TGA codon in COI is assigned for Trp (EHARA et al. 2000; INAGAHI et al. 1998; KNIGHT et al. 2001 and citations within). The clustering of several sequences outside the Chrysophyceae (however without support) lead to the assumption of the occurrence of multiple copies, homologenous or paralogous genes (see Fig 3). This is a known problem and was e.g. found in naked lobose amoebae as well (NAssonova et al. 2010). Even if paralogous genes are distinguishable in studies based on clonal isolates, they are difficult to recognize in NGS studies. Furthermore, we encountered problems in the amplification of the marker gene. Our chosen primers seemed to be too constricted, and marker genes of several strains could not be amplified. In diatoms, different COI primers were used for raphid pennates and centric diatoms (EvANS et al. 2007); in fact, different COI primers were even needed for different ciliate genera (BARTH et al. 2006; LyNN et al. 2006).

Massive parallel sequencing techniques provide a sufficient sequence depth for environmental studies, yet, most results are based on short sequencing reads only (MAssana et al. 2015; DE VARGas et al. 2015; LE BESCOT et al. 2016). To receive reliable information about species compositions and biodiversity patterns it is important to use a well suited genetic marker. The marker should offer the advantage of a highly variable region, which can be amplified by universal primers and offers good background information in existing databases to identify the reads preferable down to species level (Bock et al. 2014; ZIMMERMANN et al. 2014). Until now, the discussion on the most suitable marker gene for protists is still ongoing (PAwlowski et al. 2012). A first step towards a uniform protocol for protists was proposed by the CBOL protist working group (initiated by the consortium for the barcode of life; http://www.barcodeoflife.org/content/ community/projects?page=1). They suggested a twostep barcoding approach to address protist biodiversity (PAwlowski et al. 2012). In a nested strategy, the variable V4 region of the SSU rRNA gene is proposed as a pre-barcode, followed by a group specific barcode. Our analyses showed that the V4 region is a variable marker for chrysophytes and shows a moderate sequencing distance gap between average within group variance and between groups variance. One exception is the Paraphysomonas clade, where the variance within the clade is sometimes higher than the variance to the other analyzed clades. This is due to the relative high distance of the lineage containing Paraphysomonas vestita and relatives (our analyzed strains JBAS 37, JBAF/S47, JBAF49, JBAF/S48, JBAU44).

Adjoining the SSU rRNA gene is the ITS region, comprising the ITS1, 5.8S rRNA gene and ITS2. The ITS is often used to base taxonomic measures on the occurrence of complementary base changes within the secondary structure of either ITS1 or ITS2 or both (Luo et al. 2006; Bock et al. 2011a,b; DA Silva et al. 2016). DARIENKo et al. (2015) even recommended the use of the V9 and ITS region as barcode for the green algae Coccomyxa. Our analyses of the ITS showed a high degree of genetic diversity (see Fig 6, table 1) and variance in length (data not shown), hampering the unambiguously aligning of sequences between clades. Similar difficulties were already reported from ŠKALOUdOVÁ \& ŠKALOUD (2013). The secondary structure may help by aligning diverse sequences, but so far different models exist for members of the Chrysophyceae (Š́Kaloudová \& ŠKKALOUd 2013; AnKEnBRAND et al. 2015). As we could show with the Ochromonadales, an alignment between clades of this highly variable region is not possible without a general model. Nevertheless, even without secondary structure information, the ITS offers high resolution to distinguish related species within clades as already demonstrated (JosT et al. 2010; ŠKaloud et al. 2012).

To conclude, our results showed the importance of a detailed evaluation of phylogenetic markers for addressing taxonomic and biodiversity questions. Nearly all markers analyzed in this study show a promising variable region for distinguishing phylogenetic lineages. The ITS, LSU rRNA gene and COI are the most diverse marker in terms of genetic distances. In addition, also the V4 region of the SSU rRNA gene shows a promising high variability to distinguish phylogenetic lineages. The use of the SSU-ITS region or the D1-D2 region of the LSU rRNA gene is to be preferred to $\mathrm{COI}$ in order to avoid the potentially misleading clustering of some strains.

\section{ACKNOWLedGements}

We thank Verena Jaschik and Karin Pfandl for technical assistance and sequencing of strains. Funding of the study by the DFG Projekt BO 3245/17-2 and DFG Projekt BO 3245/2-1 is gratefully acknowledged.

\section{REFERENCES}

Andersen, R. A.; Van De Peer, Y.; Potter, D.; Sexton, J. P.; Kanachi, M. \& Lajeunesse, T. (1999): Phylogenetic analysis of the SSU rRNA from members of the Chrysophyceae. - Protist 150: 71-84.

AnKenbrand, M. J.; Keller, A.; Wolf, M.; Schultz, J. \& FORSTER, F. (2015): ITS2 Database V: Twice as Much. - Mol. Biol. Evol. 32: 3030-3032. 
Annenkova, N. V.; Hansen, G.; Moestrup, O. \& Rengefors, K. (2015): Recent radiation in a marine and freshwater dinoflagellate species flock. - ISME J 9: 18211834.

Barth, D.; Krenek, S.; Fokin, S. I. \& Berendonk, T. U. (2006): Intraspecific genetic variation in Paramecium revealed by mitochondrial cytochrome c oxidase I sequences. - J. Eukaryot. Microbiol. 53: 20-25.

Bellinger, E. G. \& Sigee, D. C. (2013): Freshwater Algae. -271 pp., John Wiley \& Sons, Ltd, Chichester, West Sussex.

Bock, C.; Krienitz, L. \& Proschold, T. (2011): Taxonomic reassessment of the genus Chlorella (Trebouxiophyceae) using molecular signatures (barcodes), including description of seven new species. - Fottea 11: 293-312.

Bock, C.; Medinger, R.; Jost, S.; Psenner, R. \& Boenigk, J. (2014): Seasonal variation of planktonic chrysophytes with special focus on Dinobryon. - Fottea 14: 179-190.

Bock, C.; Proeschold, T. \& Krienitz, L. (2010): Two new Dictyosphaerium-morphotype lineages of the Chlorellaceae (Trebouxiophyceae): Heynigia gen. nov. and Hindakia gen. nov. - Eur. J. Phycol. 45: 267-277.

Bock, C.; Proschold, T. \& Krienitz, L. (2011): Updating the genus Dictyosphaerium and description of Mucidosphaerium gen. nov. (Trebouxiophyceae) based on morphological and molecular data. - J. Phycol. 47: 638-652.

BoEnIGK, J. \& ARNDT, H. (2002): Bacterivory by heterotrophic flagellates: community structure and feeding strategies. - Antonie Van Leeuwenhoek International Journal of General and Molecular Microbiology 81: 465-480.

Boenigk, J.; Pfandl, K.; Stadler, P. \& Chatzinotas, A. (2005): High diversity of the 'Spumella-like' flagellates: an investigation based on the SSU rRNA gene sequences of isolates from habitats located in six different geographic regions. - Environ. Microbiol. 7: 685-697.

Darienko, T.; Gustavs, L.; Eggert, A.; Wolf, W. \& ProsCHOLD, T. (2015): Evaluating the Species Boundaries of Green Microalgae (Coccomyxa, Trebouxiophyceae, Chlorophyta) Using Integrative Taxonomy and DNA Barcoding with Further Implications for the Species Identification in Environmental Samples. Plos One 10: e0127838.

De Vargas, C.; Audic, S.; Henry, N.; Decelle, J.; Mahe, F.; Logares, R.; Lara, E.; Berney, C.; Le Bescot, N.; Probert, I.; Carmichael, M.; Poulain, J.; Romac, S.; Colin, S.; Aury, J. M.; Bittner, L.; Chaffron, S.; Dunthorn, M.; Engelen, S.; Flegontova, O.; Guidi, L.; HoraK, A.; JaIllon, O.; Lima-Mendez, G.; LuKes, J.; Malviya, S.; Morard, R.; Mulot, M.; Scalco, E.; Siano, R.; Vincent, F.; Zingone, A.; Dimier, C.; Picheral, M.; Searson, S.; Kandels-Lewis, S.; Acinas, S. G.; Bork, P.; Bowler, C.; Gorsky, G.; Grimsley, N.; Hingamp, P.; Iudicone, D.; Not, F.; Ogata, H.; Pesant, S.; Raes, J.; Sieracki, M. E.; Speich, S.; Stemmann, L.; Sunagawa, S.; WeissenBach, J.; Wincker, P.; Karsenti, E. \& Tara Oceans, C. (2015): Eukaryotic plankton diversity in the sunlit ocean. - Science 348: 1-12.

Ehara, M.; Inagaki, Y.; Watanabe, KI. \& Ohama, T. (2000): HYPERLINK "https://www.ncbi.nlm.nih.gov/ pubmed/10672441" Phylogenetic analysis of diatom coxI genes and implications of a fluctuating GC content on mitochondrial genetic code evolution. - Curr Genet 37: 29-33.

Evans, K. M.; Wortley, A. H. \& Mann, D. G. (2007): An assessment of potential diatom "barcode" genes (cox1, rbcL, 18S and ITS rDNA) and their effectiveness in determining relationships in Sellaphora (Bacillariophyta): - Protist 158: 349-364.

Findenig, B. M.; Chatzinotas, A. \& Boenigk, J. (2010): Taxonomic and ecological characterization of stomatocysts of Spumella-like flagellates (Chrysophyceae) - J. Phycol. 46: 868-881.

Finlay, B. J. \& Esteban, G. F. (1998): Freshwater protozoa: biodiversity and ecological function. - Biodivers. Conserv. 7: 1163-1186.

Garcia Da Silva, T.; Bock, C.; Leite Sant'anna, C.; Lacativa Bagatini, I.; Wodniok, S. \& Vieira, A. A. H. (2016): Selenastraceae (Sphaeropleales, Chlorophyceae): rbcL, $18 \mathrm{~S}$ rDNA and ITS-2 secondary structure enlightens traditional taxonomy, with description of two new genera, Messastrum gen. nov. and Curvastrum gen. nov. - Fottea 17: 1-19.

Grossmann, L.; Bock, C.; Schweikert, M. \& Boenigk, J. (2016): Small but Manifold - Hidden Diversity in "Spumella-like Flagellates". - J. Eukaryot. Microbiol. DOI: 10.1111/jeu.12287.

Gunderson, J.; Mccutchan, T. \& Sogin, M. (1986): Sequence of the small subunit ribosomal RNA gene expressed in the bloodstream stages of Plasmodium berghei: evolutionary implications. - The Journal of protozoology 33: 525-529.

Hepperle, D. (2004): Align Ver. 07/04@. Multisequence alignment-editor and preparation/manipulation of phylogenetic datasets. Win32-Version.: Distributed by the author via: http://www. sequentix. de.

Inagaki, Y.; Ehara, M.; Watanabe, KI; Hayashi-Ishimaru, Y. \& Онама, Т. (1998): Directionally evolving genetic code: the UGA codon from stop to tryptophan in mitochondria. - J Mol Evol.47: 378-84.

Jo, B. Y.; Shin, W.; Kim, H. S.; Siver, P. A. \& Andersen, R. A. (2013): Phylogeny of the genus Mallomonas (Synurophyceae) and descriptions of five new species on the basis of morphological evidence. - Phycologia 52: $266-278$.

Jobb, G.; Von Haeseler, A. \& Strimmer, K. (2004): TREEFINDER: a powerful graphical analysis environment for molecular phylogenetics - art. no. 18 (Retracted article. See vol. 15, 243, 2015): - BMC Evol. Biol. 4.

Jost, S.; Medinger, R. \& Boenigk, J. (2010): Cultivation-independent species identification of Dinobryon species (Chrysophyceae) by means of multiplex singlecell PCR. - J. Phycol. 46: 901-906.

Kammerlander, B.; Breiner, H.-W.; Filker, S.; Sommaruga, R.; Sonntag, B. \& Stoeck, T. (2015): High diversity of protistan plankton communities in remote high mountain lakes in the European Alps and the Himalayan mountains. - FEMS Microbiol. Ecol. 91: fiv010.

Klaveness, D.; Brate, J.; Patil, V.; Shalchian-Tabrizi, K.; Kluge, R.; Gislerod, H. R. \& JAKOBSEN, K. S. (2011): The $18 \mathrm{~S}$ and $28 \mathrm{~S}$ rDNA identity and phylogeny of the common lotic chrysophyte Hydrurus foetidus. Eur. J. Phycol. 46: 282-291.

Knight, RD; Freeland, SJ \& LANDweber LF. (2001): Rewir- 
ing the keyboard: evolvability of the genetic code. - Nat Rev Genet: 49-58.

Krienitz, L. \& Bock, C. (2012): Present state of the systematics of planktonic coccoid green algae of inland waters. - Hydrobiologia 698: 295-326.

Le Bescot, N.; Mahe, F.; Audic, S.; Dimier, C.; Garet, M. J.; Poulain, J.; Wincker, P.; De Vargas, C. \& Siano, R. (2016): Global patterns of pelagic dinoflagellate diversity across protist size classes unveiled by metabarcoding. - Environ. Microbiol. 18: 609-626.

Leliaert, F.; Verbruggen, H.; Vanormelingen, P.; Steen, F.; Lopez-Bautista, J. M.; Zuccarello, G. C. \& De Clerck, O. (2014): DNA- based species delimitation in algae. - Eur. J. Phycol. 49: 179-196.

Liu, H.; Aris-Brosou, S.; Probert, I. \& De Vargas, C. (2010): A Time line of the Environmental Genetics of the Haptophytes. - Mol. Biol. Evol. 27: 161-176.

López-García, P.; Philippe, H.; Gail, F. \& Moreira, D. (2003): Autochthonous eukaryotic diversity in hydrothermal sediment and experimental microcolonizers at the Mid-Atlantic Ridge. - P. Natl. Acad. Sci. USA 100: 697-702.

Luo, W.; Pflugmacher, S.; Proschold, T.; Walz, N. \& KriENITZ, L. (2006): Genotype versus phenotype variability in Chlorella and Micractinium (Chlorophyta, Trebouxiophyceae): - Protist 157: 315-333.

Lynn, D. H. \& Struder-KypKe, M. C. (2006): Species of Tetrahymena identical by small subunit rRNA gene sequences are discriminated by mitochondrial cytochrome c oxidase I gene sequences. - J. Eukaryot. Microbiol. 53: 385-387.

Massana, R.; Gobet, A.; Audic, S.; Bass, D.; Bittner, L.; Boutte, C.; Chambouvet, A.; Christen, R.; Claverie, J. M.; Decelle, J.; Dolan, J. R.; Dunthorn, M.; EdVARDSEN, B.; Forn, I.; Forster, D.; GuILlou, L.; JaILlon, O.; Kooistra, W.; Logares, R.; Mahe, F.; Not, F.; Ogata, H.; Pawlowski, J.; Pernice, M. C.; Probert, I.; Romac, S.; Richards, T.; Santini, S.; Shalchian-Tabrizi, K.; Siano, R.; Simon, N.; Stoeck, T.; Vaulot, D.; Zingone, A. \& De Vargas, C. (2015): Marine protist diversity in European coastal waters and sediments as revealed by high-throughput sequencing. - Environ. Microbiol. 17: 4035-4049.

Medinger, R.; Nolte, V.; Pandey, R. V.; Jost, S.; Ottenwaelder, B.; Schloetterer, C. \& Boenigk, J. (2010): Diversity in a hidden world: potential and limitation of next-generation sequencing for surveys of molecular diversity of eukaryotic microorganisms. - Mol. Ecol. 19: 32-40.

Meyer, C. P. \& Paulay, G. (2005): DNA barcoding: Error rates based on comprehensive sampling. - PLoS Biol. 3: 2229-2238.

Miller, M.A.; Pfeiffer, W., \& Schwartz, T. (2010): Creating the CIPRES Science Gateway for inference of large phylogenetic trees. - Proceedings of the Gateway Computing Environments Workshop (GCE): $1-8$.

Nassonova, E.; Smirnov, A.; Fahrni, J. \& Pawlowski, J. (2010): Barcoding Amoebae: Comparison of SSU, ITS and COI Genes as Tools for Molecular Identification of Naked Lobose Amoebae. - Protist 161: $102-115$

Nolte, V.; Pandey, R. V.; Jost, S.; Medinger, R.; OttenWAelder, B.; Boenigk, J. \& Schloetterer, C. (2010): Contrasting seasonal niche separation between rare and abundant taxa conceals the extent of protist di- versity. - Mol. Ecol. 19: 2908-2915.

Padisák, J.; Krienitz, L.; Scheffler, W.; Koschel, R.; Kristiansen, J. \& Grigorszky, I. (1998): Phytoplankton succession in the oligotrophic Lake Stechlin (Germany) in 1994 and 1995. - Hydrobiologia 370: 179-197.

Pawlowski, J.; Audic, S.; Adl, S.; Bass, D.; Belbahri, L.; Berney, C.; Bowser, S. S.; Cepicka, I.; Decelle, J.; Dunthorn, M.; Fiore-Donno, A. M.; Gile, G. H.; Holzmann, M.; Jahn, R.; JiRKU, M.; Keeling, P. J.; Kostka, M.; Kudryavtsev, A.; Lara, E.; LuKes, J.; Mann, D. G.; Mitchell, E. A. D.; Nitsche, F.; Romeralo, M.; Saunders, G. W.; Simpson, A. G. B.; Smirnov, A. V.; Spouge, J. L.; Stern, R. F.; Stoeck, T.; Zimmermann, J.; Schindel, D. \& De Vargas, C. (2012): CBOL Protist Working Group: Barcoding Eukaryotic Richness beyond the Animal, Plant, and Fungal Kingdoms. - PLoS Biol. 10.

Petersen, G.; Seberg, O.; Davis, J. I.; Goldman, D. H.; Stevenson, D. W.; Campbell, L. M.; Michelangeli, F. A.; Specht, C. D.; Chase, M. W. \& Fay, M. F. (2006): Mitochondrial data in monocot phylogenetics. - Aliso 22: 52-62.

Pfandl, K.; Chatzinotas, A.; Dyal, P. \& Boenigk, J. (2009): SSU rRNA gene variation resolves population heterogeneity and ecophysiological differentiation within a morphospecies (Stramenopiles, Chrysophyceae): - Limnol. Oceanogr. 54: 171-181.

Piganeau, G.; Eyre-Walker, A.; Grimsley, N. \& Moreau, H. (2011): How and Why DNA Barcodes Underestimate the Diversity of Microbial Eukaryotes. - Plos One 6: X-X.

Rambaut A. \& Drummond, A.J. (2007): Tracer v1.4. Available from http://beast.bio.ed.ac.uk/Tracer

Rogers, J. E.; Leblond, J. E. D. \& Moncreiff, C. A. (2006): Phylogenetic relationship of Alexandrium mondatum (Dinophyceae) to other Alexandrium species based on $18 \mathrm{~S}$ ribosomal RNA gene sequences. - Harmful Algae 5: 275-280.

Rотт, E. (1988): Some aspects of the seasonal distribution of flagellates in mountain lakes.. - Hydrobiologia 161: 159-170.

SAUNDERS, G. W. (2005): Applying DNA barcoding to red macroalgae: a preliminary appraisal holds promise for future applications. - Philosophical Transactions of the Royal Society of London B: Biological Sciences 360: 1879-1888.

Scoble, J. M. \& Cavalier-Smith, T. (2014): Scale evolution in Paraphysomonadida (Chrysophyceae): Sequence phylogeny and revised taxonomy of Paraphysomonas, new genus Clathromonas, and 25 new species. - Eur. J. Protistol. 50: 551-592.

Silberfeld, T.; Leigh, J. W.; Verbruggen, H.; Cruaud, C.; De Reviers, B. \& Rousseau, F. (2010): A multi-locus time-calibrated phylogeny of the brown algae (Heterokonta, Ochrophyta, Phaeophyceae): Investigating the evolutionary nature of the "brown algal crown radiation”. - Mol. Phylogen. Evol. 56: 659-674.

ŠKaloud, P.; Kristiansen, J. \& ŠKaloudová, M. (2013): Developments in the taxonomy of silica-scaled chrysophytes - from morphological and ultrastructural to molecular approaches. - Nord. J. Bot. 31: 385-402.

ŠKaloud, P.; KynČlová, A.; Benada, O.; Kofroñová, O. \& ŠKaloudovÁ, M. (2012): Toward a revision of the genus Synura, section Petersenianae (Synurophyceae, 
Heterokontophyta): morphological characterization of six pseudo-cryptic species. - Phycologia 51: 303-329.

ŠKaloud, P.; ŠKaloudová, M.; ProchÁzkovÁ,,A. \& NĚmcovÁ, Y. (2014): Morphological delineation and distribution patterns of four newly described species within the Synura petersenii species complex (Chrysophyceae, Stramenopiles): - Eur. J. Phycol. 49: 213-229.

ŠKaloudovÁ, M. \& ŠKaloud, P. (2013): A new species of Chrysosphaerella (Chrysophyceae: Chromulinales), Chrysosphaerella rotundata sp. nov., from Finland. Phytotaxa 130: 34-42.

STAMATAKIS, A. (2014): RAxML version 8: a tool for phylogenetic analysis and post-analysis of large phylogenies. - Bioinformatics 30: 1312-1313.

Stoeck, T.; Przybos, E. \& Dunthorn, M. (2014): The D1-D2 region of the large subunit ribosomal DNA as barcode for ciliates. - Molecular Ecology Resources 14: 458-468.

Swofford, D. L. (1993): Phylogenetic analysis using parsimony. - Champaign, IL: Illinois Natural History Survey.

Tamura, K.; Peterson, D.; Peterson, N.; Stecher, G.; Nei, M. \& Kumar, S. (2011): MEGA5: Molecular Evolutionary Genetics Analysis Using Maximum Likelihood, Evolutionary Distance, and Maximum Parsimony Methods. - Mol. Biol. Evol. 28: 2731-2739.

Thompson, J. D.; Higgins, D. G. \& Gibson, T. J. (1994): CLUSTAL W: improving the sensitivity of progressive multiple sequence alignment through sequence weighting, position-specific gap penalties and weight matrix choice - Nucleic Acids Res. 22: 4673-4680.

Tolotti, M.; Manca, M.; Angeli, N.; Morabito, G.; Thaler, B.; Rotт, E. \& Stuchlik, E. (2006): Phytoplankton and zooplankton associations in a set of Alpine high altitude lakes: Geographic distribution and ecology.Hydrobiologia 562: 99-122.

Tolotti, M.; Thies, H.; Cantonati, M.; Hansen, C. M. E. \& Thaler, B. (2003): Flagellate algae (Chrysophyceae, Dinophyceae, Cryptophyceae) in 48 high mountain lakes of the Northern and Southern slope of the Eastern Alps: biodiversity, taxa distribution and their driving variables. - Hydrobiologia 502: 331-348.

Veselá, J.; UrbánkovÁ, P.; Černá, K. \& Neustupa,J (2012): Ecological variation within traditional diatom morphospecies: diversity of Frustulia rhomboides sensu lato (Bacillariophyceae) in European freshwater habitats. - Phycologia 51: 552-561.

White, T. J.; Bruns, T.; Lee, S. \& Taylor, J. (1990): Amplification and direct sequencing of fungal ribosomal RNA genes for phylogenetics. - PCR protocols: a guide to methods and applications 18: 315-322.

Wylezich, C.; Nies, G.; Mylnikov, A. P.; Tautz, D. \& ARndt, H. (2010): An Evaluation of the Use of the LSU rRNA D1-D5 Domain for DNA-based Taxonomy of Eukaryotic Protists. - Protist 161: 342-352.

Zimmermann, J.; Abarca, N.; EnK, N.; Skibbe, O.; Kusber, W.-H. \& JAHN, R. (2014): Taxonomic Reference Libraries for Environmental Barcoding: A Best Practice Example from Diatom Research. - Plos One 9: e108793.
Supplementary material

the following supplementary material is available for this article:

Table S1. Origin of isolates and NCBI accession numbers of the different gene markers

Table S2. Primer used in the study

Table S3. Estimates of average evolutionary divergence over sequence pairs within groups for selected gene markers.

Table S4. Estimates of average evolutionary divergence between groups for selected gene markers.

Figure S1. Complete phylogeny of the chrysophytes obtained by maximum likelihood inference of the SSU rDNA dataset.

Figure S2. Complete phylogeny of the chrysophytes obtained by maximum likelihood inference of the LSU D1-D2 rDNA dataset.

Figure S3. Phylogeny of the chrysophytes obtained by maximum likelihood inference of the 5.8S rDNA dataset.

Figure S4. Complete phylogeny of the chrysophytes obtained by maximum likelihood inference of the COI dataset.

This material is available as part of the online article (http:// fottea.czechphycology.cz/contents)

(C) Czech Phycological Society (2017)

Received November 8, 2016

Accepted February 6, 2017 